Article

\title{
Engaging the Private Homeowner: Linking Climate Change and Green Stormwater Infrastructure
}

\author{
Thomas Beery \\ Minnesota Sea Grant, University of Minnesota, Duluth, MN 55812, USA; tbeery@d.umn.edu \\ Received: 15 November 2018; Accepted: 13 December 2018; Published: 15 December 2018
}

check for updates

\begin{abstract}
Current and projected climate change in the Minnesota Lake Superior Coastal Area indicates an increase in frequency and intensity of extreme rainfall. One key outcome of this change is a subsequent potential increase in stormwater runoff, a concern exacerbated by the region's shallow, often clay soils and exposed bedrock, along with highly impervious urban surfaces. This situation, coupled with public perception of climate change that is increasingly inclusive of severe weather, highlights an opportunity to apply green infrastructure to the challenge of stormwater management, referred to as green stormwater infrastructure. In addition to coordinated public action at local, state, and national levels, there is a role for the private landowner to participate in this form of climate adaptation. Private citizens have an opportunity to both protect their home and property while contributing to overall stormwater management for the community in which they live. Focus group research was conducted to better understand outreach and involve local residents in the creation of a tool to assist private green stormwater infrastructure efforts. Results of the focus group sessions were analyzed, and key themes emerged from the data to guide this process and support private home/landowner action. It is recommended that a fifth domain be added to the typology for public and private roles in climate adaptation, i.e. private adaptation for public and private benefit.
\end{abstract}

Keywords: climate adaptation; climate change; climate resilience; green stormwater infrastructure; focus group; Minnesota Lake Superior Coastal Area; stormwater management

\section{Introduction}

Over the weekend of 15-17 June 2018, strong storms hit the Western Lake Superior region. According to the National Weather Service, up to 4 inches of rain fell in some coastal areas of Minnesota. The totals were much higher to the east in Wisconsin and Michigan, with parts of the Lake Superior Watershed receiving up to 7 inches. One rain gauge in the area recorded 6.75 inches of rain in just over four hours [1]. The outcome of such an intense and large rainfall was flooding. The Associated Press noted on 19 June that the flooding was responsible for three deaths and left widespread damage throughout the region, with Houghton, Michigan experiencing significant loss [2]. Images of buckled roads from Houghton were reminiscent of a 2012 rain event in Duluth, Minnesota, when a severe storm dropped 5-10 inches of rain overnight on already saturated soils, causing flash flooding and extensive damage (see Figure 1). 


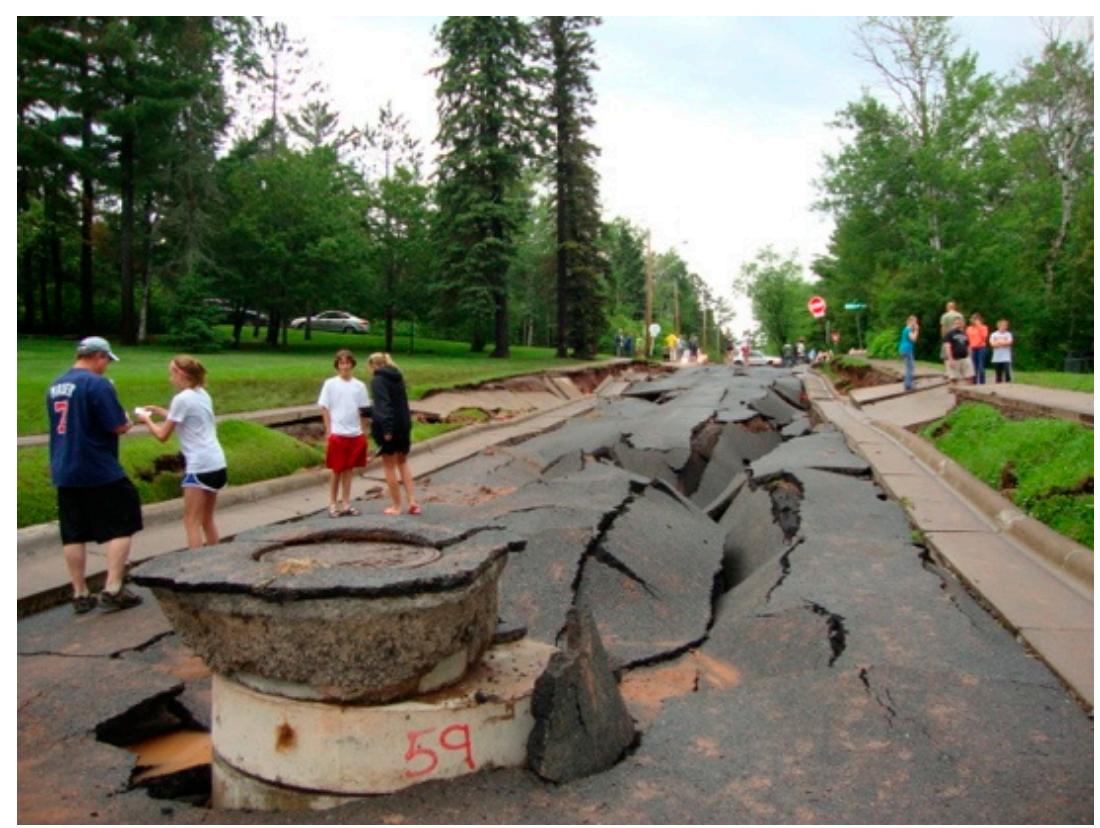

Figure 1. Image from flood destruction in Duluth, Minnesota in June 2012 (photo: Minnesota Sea Grant).

While devastating, these severe weather events are not surprising given climate trends for the Minnesota Lake Superior Coastal Area (hereafter MLSCA, see Figure 2). The Minnesota State Climatology Office has identified three primary climate change trends currently impacting this area [3]. The MLSCA is:

1. Becoming warmer and wetter.

2. Experiencing a loss of winter cold, most notably, a warming of winter overnight temperatures.

3. Experiencing an increase in frequency and intensity of extreme rainfall events.

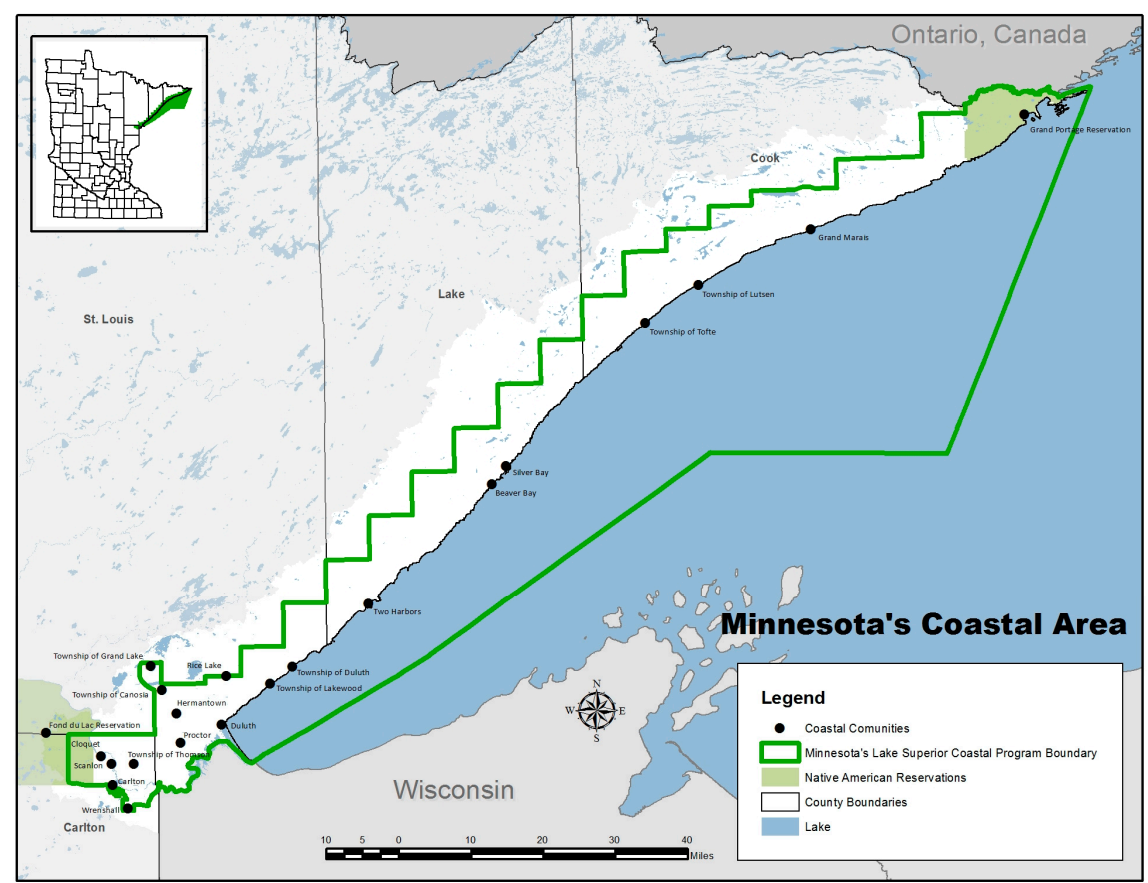

Figure 2. A map of the Minnesota Lake Superior Coastal Area (MLSCA).

It is the third noted climate change trend of extreme rainfall with more frequent and larger events that relates directly to the focus of this study. Severe weather appears to be emerging as 
a symbol of climate change that resonates with the public. A recent study shows that Americans increasingly connect climate change with real-life weather [4]. A shift away from climate change images of ice-floes and polar bears may be a sign that many people are thinking about climate change in new, close-to-home ways [5]. This current research provides an opportunity to take advantage of evolving climate change awareness. The aim of this study is to use this awareness as a part of efforts to engage local residents in climate resilience, specifically through the design of a locally appropriate tool to support homeowner use of green stormwater infrastructure.

\subsection{Climate Resilience}

Resilience refers to the capacity of a system to adapt to disturbance in ways that allow the system to reorganize, while maintaining function and identity [6,7]. Climate resilience puts the disruption focus on climate change and is defined as the ability of an entity or region to survive disruption, while anticipating, adapting, and thriving in the face of climate-based change. In this study, the idea of climate resilience is applied to the MLSCA. The reason for the narrow geographic focus is based on the overall importance of localizing climate adaptation efforts $[8,9]$. Research shows that the local level (with public and private efforts) plays an important role in the implementation of climate adaptation [10]. More specifically, localizing adaptation is important due to relevant and specific climatological, physical, ecological, and social/cultural factors that make one place distinct from another. For example, some of the physical and ecological factors that make the MLSCA unique include: An expanse of Laurentian mixed forest, extensive exposed bedrock, areas of shallow and clay soils, a band of significant topography running NE-SW across the region, numerous cold, fast-moving, short streams (10-15 miles long) draining to Lake Superior, etc. [11]. Along with these physical/ecological factors, there are social dimensions of community life that factor into place identity as well [12]. For example, relevant socioeconomic factors in the MLSCA include: A history of resource extraction, economic reliance on tourism, low population growth, an aging urban infrastructure, etc. Pulling together all of the physical, ecological, and social factors with the previously noted climate trend of more extreme rainfall events underscores the regional importance of green stormwater infrastructure in comprehensive climate adaptation efforts.

\subsection{Stormwater Management}

A very brief history of stormwater management is useful as we consider the relationship with green stormwater infrastructure and climate adaptation. Barbosa, Fernandes, and David [13] highlight a history of stormwater management that can be traced back to ancient Greek and Roman times. The long history is based largely on the importance of stormwater management for public health and environmental quality. Throughout this history, stormwater has been considered either/both a water quantity or/and water quality problem [14], and contemporary stormwater management has developed largely in response to water quality concerns and eventual water quality mandates [15]. Specifically, contemporary stormwater management efforts have been designed to: Improve the quality of stormwater entering natural waterways, reduce erosion (volume of runoff), mitigate rapid temperature change, and increase groundwater recharge (water cycling) [14,15].

Barbosa et al. [13] contend that the perception of stormwater has changed considerably during the centuries and especially in recent years-for example, the development of a strong awareness of the difference between storm sewers and sanitary sewer systems. It is argued here that another major change in perception is both needed and slowly underway-one that emphasizes the role of green infrastructure in stormwater management, i.e., green stormwater infrastructure [16], as a key part of climate adaptation efforts. Evidence indicates that this change in perception is happening-for example, the growing call to embed climate adaptation into a wider range of municipal functions in Australia, Europe, and North America [17-20].

The MLSCA is experiencing aging infrastructure, increasing urbanization, and an expansion of impervious surfaces. These changes, along with additional disruption of nonhuman landscapes, 
is leading to reduced capacity for the retention and infiltration of stormwater. Couple this reduced capacity with the impacts of an increased experience of extreme rainfall in the MLSCA makes awareness of the connection between stormwater management and climate adaptation critical. Evidence of this change in awareness can be seen where the vulnerability, consequences, and adaptation planning scenarios (VCAPS) process has been implemented [21]. VCAPS helps coastal communities characterize “... the implications of interacting climate stressors that originate stormwater, bringing all available expertise and local knowledge to bear on the problem of stormwater management, integrating local and scientific information about coupled human-environment systems, identifying management actions and their trade-offs, and facilitating planning for sustained coordination among multiple public and private entities." [21] (p. 163) Another example of the growing awareness of the important linkage between stormwater management and climate adaptation is current hazard mitigation planning in the MLSCA. Cook County (a significant part of the MLSCA, see Figure 2) is currently involved in updating their Federal Emergency Management Agency (FEMA) multihazard mitigation plan. As part of this FEMA planning, four mitigation strategies designed to reduce or eliminate the impacts of future natural hazard and disaster events are identified, including: (1) Local planning and regulations, (2) structure and infrastructure projects, (3) natural systems protection, and (4) education and awareness programs [22]. Many of the recommended actions are appropriate at multiple scales, including green stormwater infrastructure at the scale of the private home.

\subsection{Public-Private Linkage in the MLSCA}

Not surprisingly, the various levels of government in the MLSCA are highly engaged in stormwater management. In addition, the coordination of efforts across governmental units is creatively addressed in the MLSCA via the following initiatives:

- The regional stormwater protection team or RSPT is a collaboration between local municipal separate storm sewer systems (MS4s) — communities subject to regulation based on the Clean Water Act, along with partnering agencies and organizations.

- The Duluth Urban Watersheds Advisory Committee, or DUWAC, is made up of representatives from the municipalities in the Duluth urban area along with other regional organizational members. The Committee's primary purpose is to serve as an information exchange and coordinating mechanism for watershed projects in the urban area.

In addition to these creative governmental and organizational collaborations, a focus on private property stormwater management is needed. A geospatial analysis of the MLSCA indicates that 39\% of the area is privately owned [23]. This figure highlights the importance of including home and landowners of the region in stormwater management efforts. When this statistic is coupled with research indicating that people act on a perceived individual responsibility for climate change [24], the idea of coordinating public and private efforts is strengthened.

A turn to climate adaptation research may be useful to help to consider just where the private property owner fits with regard to such coordinated public effort. Tompkins and Eakin [25] created a typology for public and private roles in climate adaptation with four domains: (1) Public provision of adaptation good for public benefit; (2) public provision of adaptation goods for (largely) private benefit; (3) private adaptation for private benefit; and (4) private adaptation for public benefit. It appears that this last category might fit the research presented in this current study; however, Tompkins and Eakin state: "In this case, the benefits of individual or private action do not directly accrue back to the individual, or are so diffuse in space and time as to be intangible and abstract" [25] (p. 4). Thus, this current study argues for a fifth domain to be added to the typology: Private adaptation for public and private benefit - a domain that is characterized by private action that serves community adaptation needs (in this case green stormwater infrastructure) while also benefitting the private home/landowner. 


\subsection{Private Citizen Participation}

Recent studies of flood risk management indicates a growth beyond governmental initiative to include deeper consideration of the private sector role, for example, consideration of the purchase of flood insurance [26,27]. Such flood protection action along with an overview of the climate adaption and public engagement literature indicates that socioeconomic variables have a strong impact on whether or not an individual engages in climate or flood adaptation [27]. In addition, cognitive variables have been shown to influence adaptation behavior and intention to act positively. Households were shown to be more likely to take adaptive measures if negative or severe outcomes were expected [27-31]. For example, adaptation behavior is enhanced by the perception of high flood likelihood [29,31,32]. These findings highlighting cognitive variables are of particular interest in the MLSCA given current climate change and climate change projections that point to the potential for an increase in flooding, along with evidence of how recent flash flooding has caused extensive economic loss [33]. The Koerth et al. review and findings [27] highlight the role of cognitive variables as factors in adaptation behavior is a key element of the motivation behind this study. Their findings indicated that coastal risk management policies should promote the efficacy of household-level climate adaptation.

Further motivation for this project comes from the finding that coastal risk management policies should promote private adaptation initiative by integrating it into public adaptation strategies and efforts [27]. In addition to the climate adaptation literature, examples of projects can be found that provide evidence of engaged private citizens active in public stormwater efforts [34-36]. Previous studies in the MLSCA identified residents of a Duluth, Minnesota neighborhood that understood the connection between excess stormwater and Lake Superior water quality [37]. The study found a majority of homeowners willing to learn more about residential stormwater and runoff retention practices. Eckman and Walker found good potential “... to work with local residents to better understand and adopt stormwater management BMPs such as rain gardens or landscaping. Many households ... are interested in measures to mitigate flooded basements, waterlogged yards, and in some cases, eroded landscaping and property damage" [37] (p. 12). The findings from Eckman and Walker [37], coupled with growing community stormwater action, as evidenced by creative collaborations like the noted RSPT and DUWAC, provide hope that the very people we wish to target with quality information and action may be able to help to guide that process. Ultimately, the research question for this study was formulated out of this foundation: What input do residents of the MLSCA have for the development of a tool designed specifically to guide home/land owners of the MLSCA in green stormwater infrastructure (climate adaptation) efforts?

\section{Methods}

Based upon the research question noted in the previous section, focus group methods with qualitative analysis were deemed an appropriate methodology for this research. An initial phase of the process involved outreach to a number of public stormwater groups in the MLSCA, including the noted RSPT and DUWAC. This outreach involved seeking guidance for action in accordance to local needs. The pre-research outreach helped to shape the design and research protocol. A second preliminary step was a review of several stormwater management guides to provide a sense of how stormwater management outreach was developed in other regions.

Focus group study participants consisted of a convenience/snowball sample of public residents of the MLSCA who received an email invitation to participate in a focus group. Email invitations were generated from existing University of Minnesota Sea Grant outreach lists. Recipients were encouraged to forward the emails to friends and family. The invitation stated that the focus group session was a part of an initiative by Minnesota Sea Grant to reach out to coastal area community members interested in how private initiative may be able to serve public stormwater management efforts. The event was advertised to emphasize both participant interest and willingness to participate in stormwater management. For example, questions promoting engagement were used in the promotional outreach: "Are you interested in making your property resilient to stormwater? Are you curious how protecting 
your property from stormwater could help the greater community? Do you have two hours to be part of a focus group that will inform the creation of a Lake Superior Green Guide?" It is important to note that while focus group participation emphasized being a part of the creation of a "guide", the details of such a tool were never specified with the hope that the focus groups sessions would help to direct and shape the form of a potential future tool.

Four focus group events were held in an attempt to make the discussion opportunity accessible to a broad range of coastal area residents. The focus group discussions were held in the coastal area communities of Grand Marais, Two Harbors, and Duluth (see Figure 2). Two sessions were held in Duluth, one session targeted rural residents of the greater Duluth area, and the other targeted urban residents. Each session consisted of a presentation providing climate change projections as the context for stormwater management in the Lake Superior coastal area. Data from the Minnesota Department of Natural Resources Climatology Office were presented to provide specific climate change context. From the proposed foundation of climate resilience, the broad question of how private initiative may be able to support local government effort to manage stormwater was posed. Once this introduction and framing was concluded, a series of materials and questions were presented to engage participants in discussion. Specifically, video, websites, and printed matter were presented, and questions were posed. Discussion facilitation (approximately 1.5 hours) followed a semi-structured approach with set questions designed to elicit discussion, while allowing flexibility for additional questions or conversation direction; this flexibility made it possible to capture the unique perspectives or interests of each group. Discussion at each focus group session was recorded with participant consent and the entire process was reviewed by the Institutional Review Board of the University of Minnesota for ethical treatment of human subjects. The recordings were transcribed and then analyzed using a qualitative coding procedure known as constant comparison analysis [38]. For an overview of the analysis procedure, see Table 1 . Each session was initially analyzed independently, while Step 4 allowed for an iterative processing with a careful review of themes within and between the four sessions [39].

Table 1. Research method progression described.

\begin{tabular}{ll}
\hline Process Step and Description & \\
\hline Step 1: Open coding & The data are read, evaluated, and divided into meaningful chunks. \\
Step 2: Axial coding & The chunks are grouped into categories. \\
Step 3: Themes emerge & Themes are identified that express the key content. \\
Step 4: Group to group analysis & $\begin{array}{l}\text { Similar themes from each session are considered and refined. Unique } \\
\text { themes are identified. }\end{array}$ \\
\hline
\end{tabular}

In addition to the focus group discussion, two other data sources were analyzed as a part of the overall data collection. Firstly, each participant completed a short electronic survey to capture basic demographic data. This electronic survey format also allowed for an opportunity for participants to share additional thoughts or opinions they had not shared during the open discussion. Secondly, as participants reviewed draft text materials during the focus group sessions, many took notes and wrote comments on the draft literature; these notes were collected and reviewed as an additional data source. For a basic schematic of the analysis process, see Figure 3. 


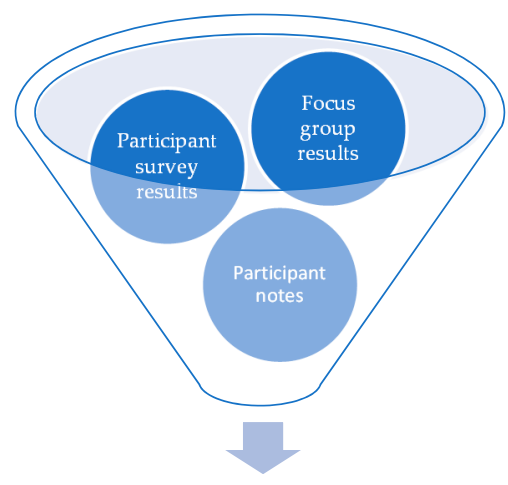

Integrated results and analysis

Figure 3. Integrated results and analysis general schematic.

\section{Results}

Thirty-three participants engaged in the four sessions. The participants ranged in age from 28 to 76 years, with an average age of 51 years. Fifty-seven percent of participants were female and $40 \%$ were male. Fifty-eight percent of participants indicated that they worked full- or part-time outside the home and $10 \%$ indicated that they worked in the home; $27 \%$ indicated that they were retired.

The electronic survey descriptive results indicate that participants are an engaged and interested group, with $77 \%$ of participants indicating that they have taken measures to manage stormwater on their private property prior to participation in the focus group. Ninety-three percent of participants indicated that they would be willing to take measures in order to manage stormwater on their property in the future. Of the $93 \%$ of participants willing to take action on their property in the future, the greatest barrier to taking such action was cost, with $67 \%$ of participants noting it as a barrier to action (see Figure 4). Only $23 \%$ indicated that a lack of information was a barrier to action.

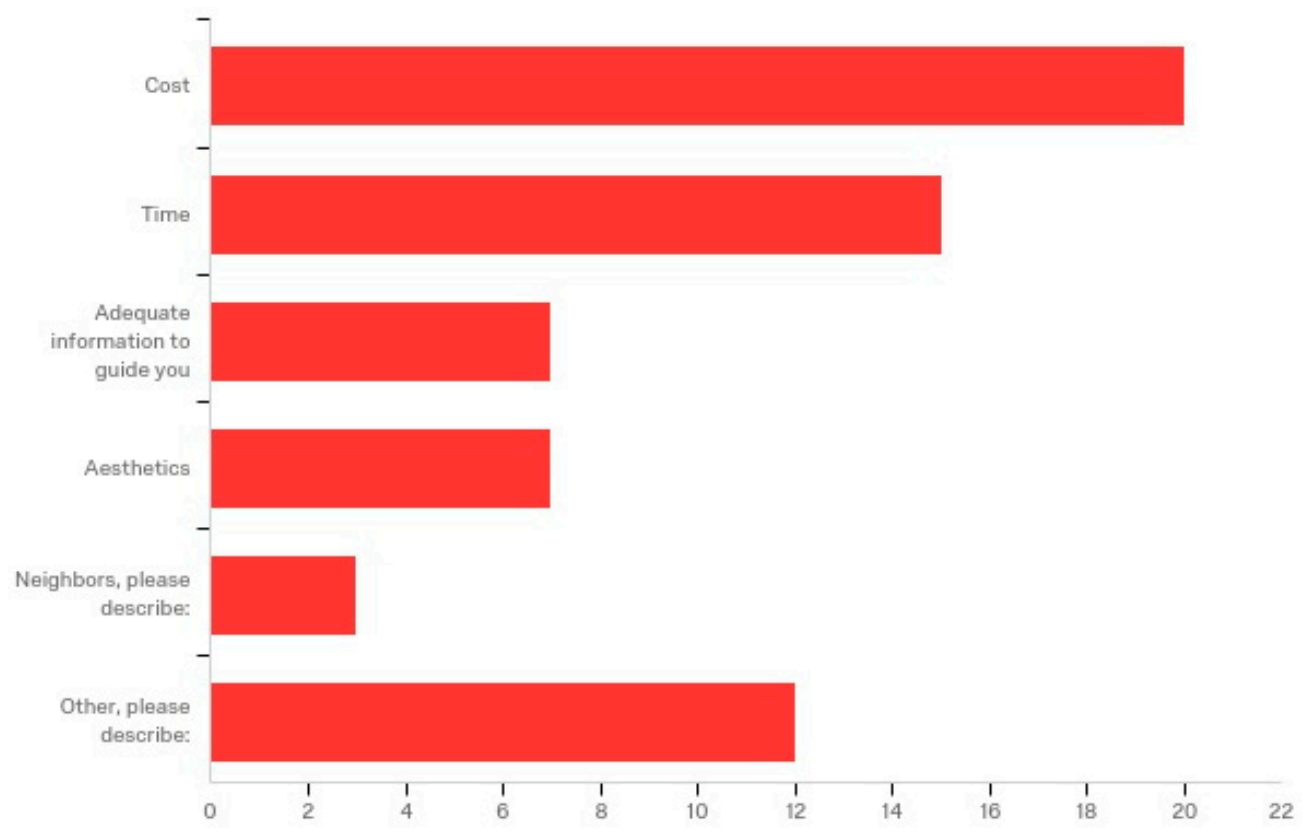

Figure 4. Barriers to taking action on private property ( $\mathrm{x}$ axis = number of participants responding to each item).

Participants indicated a wide range of motivations for their willingness to act in the future, with the greatest motivation being the ability to contribute to community stormwater management efforts (see Figure 5). It was also interesting to note that three of the five "other" comments to describe motivations indicated that the health of the Lake Superior Watershed was a motivation. 
These concerns for the Lake Superior Watershed seem to be congruent with respondents' desire to contribute to community stormwater management efforts.

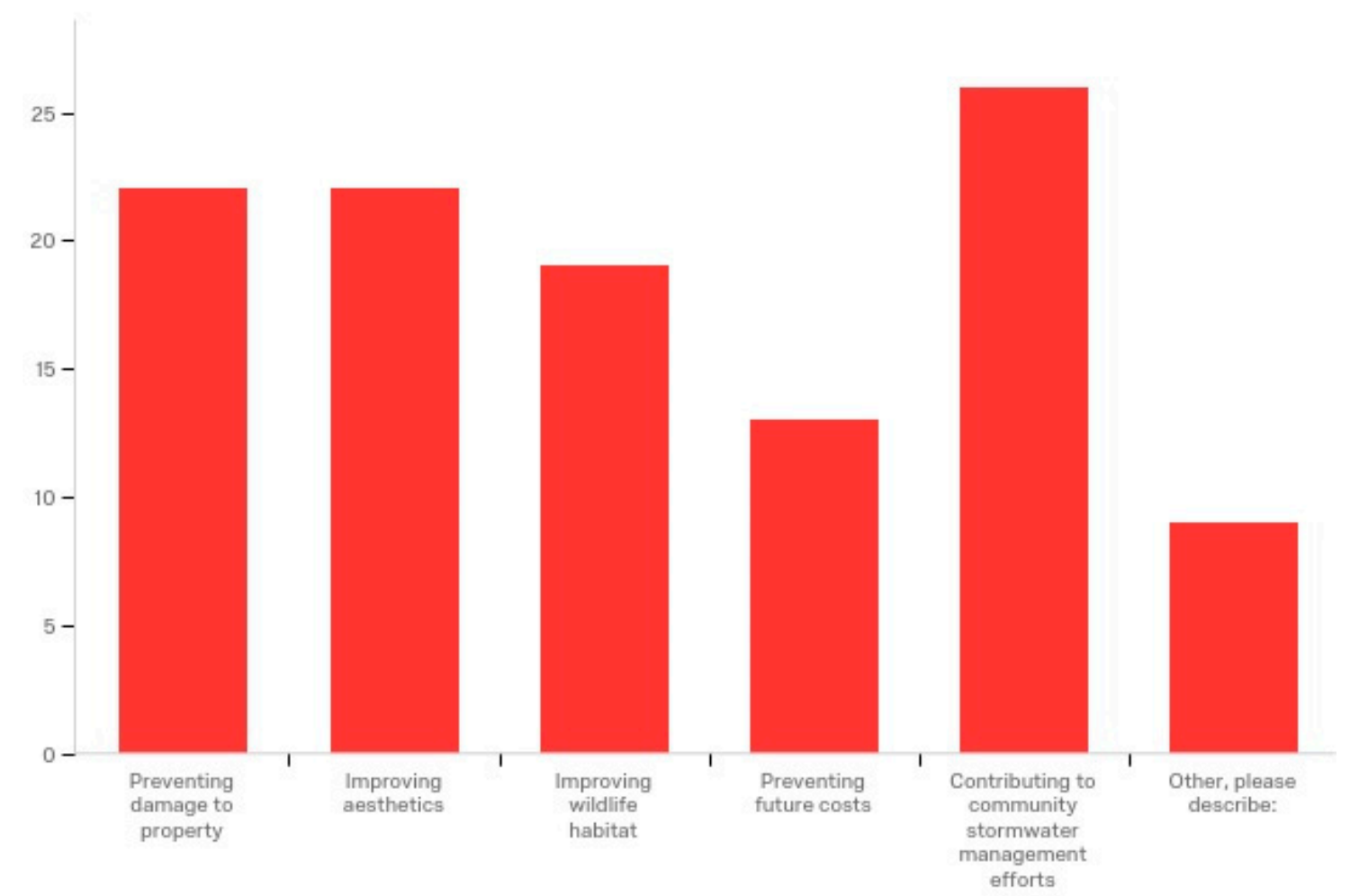

Figure 5. Participant motivations to take measures to manage stormwater in the future (y axis = number of participants responding to each item)

Another potential indicator of engagement was the finding that $47 \%$ of participants reported they did not learn anything new about climate change. While the climate change information presented was not extensive, it was up to date regarding current status and projections. Thus, a large percentage of participants came to the focus group sessions with an already established awareness of regional climate trends, supporting the characterization of the group as engaged or interested in these topics.

\subsection{Themes}

Four strong themes emerged from the constant comparison analysis process: Rationale (why?) audience (who?), content (what?), and format (how?). It is important to reiterate that while focus group participation emphasized being a part of the creation of a "guide", the details of such a tool were never specified with the hope that the focus groups sessions would help to shape the form of this future tool. Given this context, it is not surprising that these key organizational themes emerged from the discussions. While aspects of each of these is distinct, the four main themes show a great deal of overlap as well. Each theme is described via the focus group data, including identification of important subthemes. One cross-cutting subtheme, identified as part of each of the four main themes, was localizing the effort; this subtheme is explored in each theme section.

\subsubsection{Rationale}

There was a point in each session when the question of why emerged in the discussion. Participants emphasized that the goal behind such an effort needs to be clearly stated. Participants discussed how any eventual product or tool must provide a rationale that is evident to the reader/user, answering the question of "Why do I need to know this?" For example, a basic call for a clear guiding rationale came up in all of the sessions, with comments like: " ... create a rationale or background and 
explanation, reasons why people would even do this." Another example of this emphasis on rationale is that the phrase "big picture" came up a number of times during these discussions, indicating a push for guiding direction. The three basic ideas to make the rationale more clearly evident were:

- The health of waterways, primarily Lake Superior, as a narrative, for example: "Think about quality and quantity of the stormwater so close to Lake Superior and streams." The emphasis on Lake Superior as a rationale in multiple discussions may be an example of the cross-cutting subtheme of localizing the effort; Lake Superior provides a local context and motivation for action.

- The household as a narrative. This was best captured in one discussion when participants urged use of the household level as a focal point and as a way to "build support for the overall effort."

- Taking care of community as a narrative. For example, one participant described it in the following way: " . . this is part one of the whole point .... linking private responsibility and public goods. That is the start of the topic ... you are helping the overall community by taking care of what is yours." A reminder here that participants shared a wide range of motivations for their willingness to act in the future, including $87 \%$ of participants who indicated prioritizing the ability to contribute to community stormwater management efforts.

These examples of guiding rationales also make room for consideration of the theme of audience- that being the motivation of a given individual to take action. During multiple sessions, the idea that some people will want to get involved to solve their own household issues, while others may be motivated by altruistic goals of water quality and community resilience, were compared. One participant described these motivations as "me-me" motivations vs. "us-us" motivations.

\subsubsection{Audience}

The importance of keeping the audience at the forefront of planning/developing a tool was a theme in each of the focus group sessions. Identifying the target audience was one aspect of this theme, with descriptors like "engaged" and "interested" used by participants to identify key audience attributes. One participant described her fellow focus group participants by saying, "We all do this because we are passionate about this already."

The use of appropriate vocabulary was one aspect of an overlap between the theme of content and audience. Focus group participants pushed for avoidance of overly technical or scholarly language that might confuse or repel potential users. One participant urged caution as she described her work in the area, commenting: "I work with smart people, but they are not scientists. Anytime you can, use words that are more explicit to people's experiences." On this topic, another participant pointed out the use of the phrase "nature's functions" in some of the written material as much clearer than the use of the term "ecosystem services." Terminology/vocabulary examples like this were highlighted repeatedly as participants picked out phrases or terms that were useful or problematic.

An emphasis on the cross-cutting subtheme of "local" emerged in the discussion of audience and content. For example, numerous participants indicated that local images serve the local audience, that people want to see these ideas in a familiar, local, context: "I think having vegetation that appears to be local, images from Duluth or the North Shore make connections ... " The subtheme of "local" raised an interesting question of whether rural stormwater management is distinctly different from the more urban MLSCA areas of Duluth, Two Harbors, and Grand Marais. Numerous participants voiced concerns that we cannot simply create one local approach given the very different patterns of stormwater flow in rural vs. urban areas. One participant noted that much of the material used in the focus group to review, consider, and discuss was suitable for urban stormwater management/urban audience but not the rural setting and voiced the opinion: "Maybe a guide for urban and a guide for rural?" and discussion comments like "I am concerned with erosion along roadways, rural issues of ditches and culverts." 


\subsubsection{Content}

Content for a potential tool was a theme with a wide diversity of subthemes. For example, participants provided a lot of ideas for specific natural history-oriented content that could be included in a stormwater guide for homeowners, such as native plant identification, information about encouraging pollinators, discussion about the need for specific climate change information, etc. Another prominent subtheme of content was the "how-to" oriented discussions, as in the need for specific directions or technical information needed for rain garden design, gutter redirection, etc. Much of the how-to discussion was partially guided by the examples used in the focus groups to facilitate discussion. During the discussion of redirecting rainwater away from one's home, specific content ideas emerged, for example, comments and discussion: "Do you need to filter water off of a house or can it be diverted directly into the lake?" or "I have a lot of run-off that comes from my driveway and I don't really know where it's coming from ... " Out of these discussions was a subtheme of nuts and bolts or "real world" application, with discussion centered upon the need for cost, installation, maintenance, and space information to allow homeowners to make good judgements about taking action. One participant talked about the challenges they faced with rain barrels, specifically the sizing of rain barrels. A part of these "real world" discussions were the sentiments of some participants who want to take action but needed the right information to help to guide them toward the right project ("right" meaning right for one's budget, time commitment, yard, etc.). For example, in all of the focus groups, the subtheme of order was discussed, as in the importance of ordering information to guide an interested homeowner through a particular process-knowing what to do when.

As previously discussed in the rationale and audience theme sections, an important cross-cutting theme was the localization of the effort, with discussion about the content needing to reflect the local, from the choice of appropriate plants for rain garden placement to the specific geomorphology of the coastal area. For example, one participant used his experience to discuss the local challenges based on the bedrock on his property and throughout the region: "It's hard to filter because there is about 2 inches of soil on top of bedrock!"

An overlap between the themes of audience and content was evident via the breadth of content comments and questions in the focus group discussions. The quantity and depth of the questions was a good reminder of how interested people are and just how much information is needed, even for a well-informed and engaged audience.

\subsubsection{Format}

This theme emerged in the discussions repeatedly in three distinct (yet sometimes overlapping) ways, the three key subthemes of delivery, form/function, and style/design.

\section{Delivery}

The discussions related to delivery were largely based on an underlying question of what the best way is to get this information out to the public. A progression from paper/hard copy to various electronic platforms such as web-based, video, app, etc., was discussed. No clear path forward emerged from these delivery discussions; however, good consideration was applied to numerous delivery approaches. Many participants in Grand Marais noted that the (local) Cook County Homeowner's Guide was a useful tool and provides a potential model for organizing and distributing information. During this discussion of a hard copy/paper guide, numerous participants urged caution and consideration for how new information is updated or how new information replaces outdated information with regard to printed hard copy material. Similarly, while website delivery of information was promoted, concerns about website upkeep were also noted. 
Form and Function

The importance of how images are used to convey function was recurring. Numerous participants appreciated a cartoon graphic simply because the illustration was able to convey process ideas, like soil infiltration and water movement in general: "I like how it shows infiltration, it shows water going into the soil." Further, lists and other text information were critiqued during the focus group process as needing quality graphics to bring the concepts alive and to help to make this underlying processes and concepts understandable. The already mentioned content subtheme of order was also a part of format discussions, with participants wanting information that provided a "step by step approach."

Closely related to the perceived need for images to accompany lists of information was the push by many participants for infographics to tell a particular story or convey the necessary information. Also included in this subtheme of form and function were numerous discussions of the rain garden video that was used in the focus group sessions. Participants generally appreciated how that video conveyed "real world" context with regard to how the rain garden functioned and the service it provided to the homeowner.

Style and Design

As participants discussed various images in print and electronic form, a good deal of discussion was aimed at style and design. Some participants preferred diagrams, others photos, and others cartoon images in order to convey various messages. The recurring cross-cutting subtheme of "local" emerged in discussions of style and design. Participants wanted to be able to see that the depictions were local, whether it was a rain garden or a downspout, for example: "I like the picture of the pipes ... like that old Duluth building, looks like an old Duluth house, fits in ... "

\section{Discussion}

The results and analysis of the focus group research process have provided useful information to guide outreach and supports previous findings regarding private engagement in questions of public stormwater management in general [27,34-36], and specifically within the MLSCA [37]. Looking forward, climate data indicate that the current climate and projected trends highlight an increasing need for broad-based stormwater management in the MLSCA. Severe precipitation events are happening now and becoming more frequent. A lookout into the MLSCA shows motivated municipal officials and organizations working to manage current and projected stormwater. The focus group sessions add an understanding that there is a subgroup of the MLSCA population also eager and motivated to take stormwater management action on behalf of both private and public needs.

The results of this study note that the two biggest barriers to taking private action on behalf of stormwater management and climate adaptation are cost and time. Further, the focus group sessions show that participants want a "local" approach, i.e., want to know that stormwater management information for the private home/land owner is geared toward the MLSCA in approach, content, and opportunity. The intersection of these outcomes is the place where the why, who, and what findings guide the design and development of an actual tool.

\section{A Look to Vermont}

The overlap of Why, Who and What in Figure 6 is where the discussion of How emerges. Any final delivery decision must make sure to consider the details of these other three themes, and while the methodology of this study did not call for a rigorous review of available homeowner stormwater management guides as a specific step in the research process, nonetheless, guides were consulted as a part of the process. Sources were reviewed to gain an understanding of how this information and communication were developed in other places, as well as to collect examples for discussion for the focus group discussions. Despite not being the original intent of the review process, one particular 
guide emerged as an excellent fit for the MLSCA based on the focus group results, the Vermont Guide to Stormwater Management for Homeowners and Small Businesses [40].

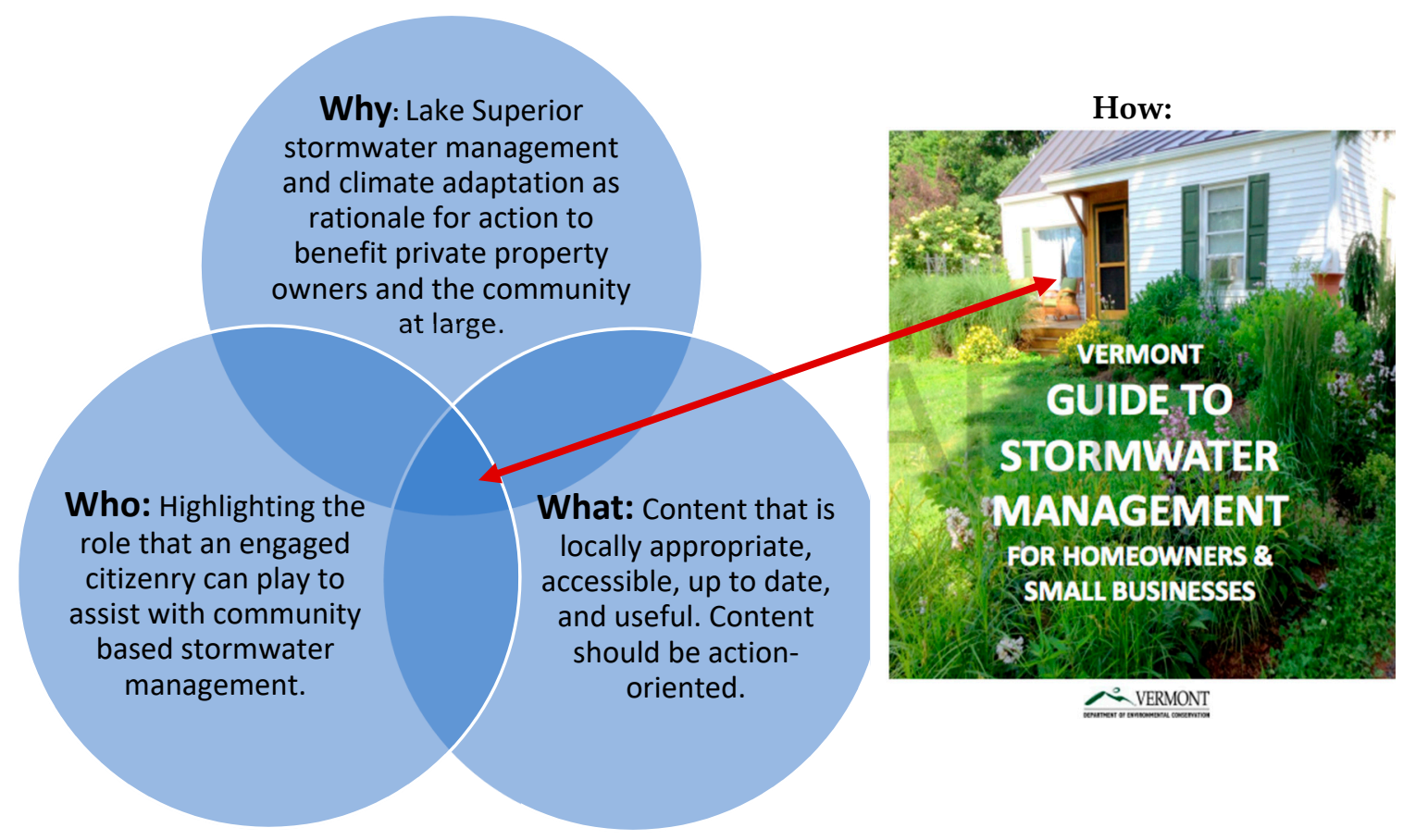

Figure 6. A synthesis of the analysis. The overlap of Why, Who, and What is How.

A topic from the focus group that came up repeatedly, a subtheme of format was the idea that whatever route this project development takes, efforts should not be duplicated, or as one participant stated: "Don't go out and spend a lot of money to reinvent the wheel." This sentiment was captured in the already reported participant survey result showing only $23 \%$ of participants indicating a lack of information as a barrier to action. Many of the engaged participants knew from previous experience that good resources exist and that the challenge was not so much one of creating, but rather of capturing and reorganizing. The turn to the Vermont Guide is evidence that this message was heard. The Vermont Guide provides a template that with noted editing will be ready and appropriate for an MLSCA audience.

Localizing the Tool

This guide will be used to provide a model for a product, a tool for action in the MLSCA based upon the findings of this research. While the cross-cutting theme of "localizing the effort" seems to be contradicted by "a look to Vermont," this point will be addressed. Consideration of the Vermont Guide based on the specific results of this study include:

1. Format is a unique blend of web based and hard copy (web-based PDF). The Vermont Guide information is designed to work as an online publication with active, useful links to provide additional information. In addition, the format also allows the information to be printed into a useful booklet.

2. Guide provides outreach to an engaged audience. This document has useful information for a broad cross-section of the public; however, the focus is skewed toward the motivated and engaged user, i.e., it is a highly action-oriented document. The guide provides content and diagrams to support action, and also provides basic cost, installation, maintenance, problem-solving, and space information to guide decision making.

3. Guide provides a rationale for action. The Vermont Guide provides two pages early in that document that address the problem of stormwater runoff and defines green stormwater 
infrastructure in the context of providing a rationale to the question of why take action? In order to make it appropriate in an MLSCA context, the health of the Lake Superior Watershed should be stressed via a short section highlighting this reason for action. The underlying impetus behind this effort, climate change trends, must also be added to provide an overall rationale that includes climate adaptation, a rationale not included in the Vermont Guide. In addition, this section could provide a reference to many other co-benefits of green infrastructure. For example, water quality protection, aesthetics, biodiversity enhancement, outdoor recreation opportunity, etc., could be highlighted.

4. Broad scope of information in a concise document. The format provides detail-rich content. The concise content provides a background to the question of just what stormwater is and specific information behind taking action. In order to make it appropriate in an MLSCA context, content regarding MLSCA soil, bedrock, and topography needs to be included (see Point 7 below).

5. The format is visually rich and uses a variety of graphic approaches to convey information. Extensive application of combined use of diagrams and pictures to provide real world context and detailed installation information is a part of the Vermont Guide format, including measurements, scale, and nonobvious content. In order to make the guide appropriate in an MLSCA context, localizing some the images is necessary (see Point 7 below).

6. Terminology defined to avoid confusion and to educate/raise awareness of stormwater management. The Vermont Guide has numerous definitions worked into the guide throughout the text that assist the reader. For example, the noted description of green stormwater infrastructure in the introduction. Careful attention to vocabulary is needed to assure clarity and local appropriateness of terminology for an MLSCA context.

7. Localized content in multiple ways. Localizing the content is apparent in the Vermont Guide in both visual images (e.g., pictures from Vermont with place labels) and content-oriented ways (e.g., link to the Vermont Agency of Natural Resources Atlas of the Vermont Agency of Natural Resources). Localizing information was the strongest cross-cutting subtheme from the research results of this study. Therefore, in order to make a revised guide appropriate in an MLSCA context, visual images and links to appropriate agencies and sources for additional information need to be localized.

8. Guide provides both rural and urban application. The State of Vermont, not unlike the MLSCA, has extensive rural areas and the Vermont Guide reflects this demographic. The range of rural to urban action possibilities is captured in the variety of practices presented in the Vermont Guide, for example, "rural driveways" to a "dry well" feature (suitable for limited urban space situations). An addition to the Vermont Guide is proposed that highlights resources for managing rural ditches common in the MLSCA drawing on the publication, The Field Guide for Maintaining Rural Roadside Ditches [41]; this publication designed for the unique and specific conditions of managing stormwater in rural northeastern Minnesota.

A final point, the cross-cutting subtheme of "local" was so strong and evident throughout all of the broad themes highlighted above that it cannot be emphasized enough. Any tool for the MLSCA must present the details of background and action that are unique to the MLSCA. Localizing will instill users with confidence that the guide is designed with their needs and realities in mind. Further, localizing will provide the critical climate change context that underlies this effort. The value in users seeing local climate change as a driver of the need for increased stormwater management via green infrastructure will contribute to climate resiliency in the MLSCA.

\section{Conclusion}

$\mathrm{s}$ This effort to link green stormwater infrastructure and climate adaptation in the private sector and take advantage of a growing awareness of trends showing public perception of climate change as inclusive of severe weather represents a tangible example of climate resilience in action. While this 
study explicitly sought participants interested and willing to participate in stormwater management, it is hoped that the lessons learned from outreach to this engaged group will help to build momentum toward broad-based private homeowner engagement in green stormwater management across the entire region. For example, drawing upon the knowledge and experience of the participants of this study may help less engaged area residents to avoid barriers to action. In addition, residents of the MLSCA may be able to see how changes in climate, specifically a currently experienced and projected increase in severe storms for the region, are a part of increasing needs for stormwater management.

Linking climate change with stormwater management also facilitates consideration of public-private benefits of coordinated efforts, i.e., providing private citizens with an opportunity to understand how the efforts they make to protect their home and property may be able to contribute to overall stormwater management for the community in which they live. Such understanding with the potential for action supports the argument in favor of a fifth domain to be added to the typology for public and private roles in climate adaptation, as presented in the introduction [25], i.e., private adaptation for public and private benefit-a domain that is characterized by private action that serves both community adaptation needs while also benefitting the private home/landowner's desire to protect private property. This study has investigated how such a domain can be supported in the content of a specific place, the MLSCA. The outcome, a proposal for a tool locally adapted to serve the MLSCA, recognizes that the front line of climate adaptation is at the local level. The recommendation to edit the Vermont Guide for use in the MLSCA highlights how climate resilience can be informed by broad-based adaptation efforts, regional climate science, and local engagement.

Funding: This research was funded in part by the Coastal Zone Management Act of 1972, as amended, administered by the Office for Coastal Management, National Oceanic and Atmospheric Administration under Award NA17NOS4190062 provided to the Minnesota Department of Natural Resources for Minnesota's Lake Superior Coastal Program.

Acknowledgments: The researcher would like to thank Marie Thoms and Jesse Schomberg of the University of Minnesota Sea Grant, Tiffany Sprague of the Natural Resources Research Institute, Rand Philips of the University of Minnesota Duluth, and Clinton Little of the Minnesota Lake Superior Coastal Program (MN DNR).

Conflicts of Interest: The author declares no conflict of interest.

\section{References}

1. Torregrossa, M. Did a Rain Gauge Really Record 1.75 Inches a Minute in U.P. Flash Flooding? 2018. Available online: https:/ /www.mlive.com/weather/index.ssf/2018/06/colossal_rainfall_rate_found_d. html (accessed on 21 June 2018).

2. Ibrahim, D. Storms batter Michigan, cause dozens of roads to collapse. The Weather Network. 18 June 2018. Available online: https:/ / www.theweathernetwork.com/us/news/articles/us-weather/flood-houghtonmichigan-wisconsin-state-of-emergency-sinkhole-storm/104879/ (accessed on 10 July 2018).

3. Blumenfeld, K. Understanding Minnesota's changing climate. In Proceedings of the Outdoor Recreation Climate Adaptation Workshop, Duluth, MN, USA, 25 October 2017.

4. Leiserowitz, A.; Smith, N. Affective imagery, risk perceptions, and climate change communication. Oxf. Res. Encycl. Clim. Sci. 2017. [CrossRef]

5. Osaka, S. Move over Polar Bears: Climate Change Has a New Symbol. 2018. Available online: https: / / grist.org/article/move-over-polar-bears-climate-change-has-a-new-symbol/ (accessed on 23 July 2018).

6. Grove, K. Resilience; Routledge: New York, NY, USA, 2018.

7. Walker, B.; Salt, B. Resilience Thinking: Sustaining Ecosystems and People in a Changing World; Island Press: Washington, DC, USA, 2012.

8. Dellinger, M. Localizing climate change action. Minn. J. Law Sci. Technol. 2013, 14, 603-668. [CrossRef]

9. Nordgren, J.; Stults, M.; Meerow, S. Supporting local climate change adaptation: Where we are and where we need to go. Environ. Sci. Policy 2016, 66, 344-352. [CrossRef]

10. Klein, J.; Juhola, S.; Landauer, M. Local authorities and the engagement of private actors in climate change adaptation. Environ. Plan. C Politics Space 2016, 35, 1055-1074. [CrossRef] 
11. Minnesota Department of Natural Resources (MN DNR). North Shore Highlands Subsection. 2018. Available online: https:/ / www.dnr.state.mn.us/ecs/212Lb/index.html (accessed on 20 June 2018).

12. Groulx, M. Prospects for Place-Based Climate Change Adaptation: An Exploration of Place, Vulnerability and Collaborative Planning in Churchill, Manitoba. Ph.D. Thesis, University of Waterloo, Waterloo, ON, Canada, 2015.

13. Barbosa, A.E.; Fernandes, J.N.; David, L.M. Key issues for sustainable urban stormwater management. Water Res. 2012, 46, 6787-6798. [CrossRef]

14. Fitzgerald, J.; Laufer, J. Governing green stormwater infrastructure: The Philadelphia experience. Local Environ. Int. J. Justice Sustain. 2017, 22, 256-268. [CrossRef]

15. Minnesota Pollution Control Agency. Municipal Stormwater (MS4). 2017. Available online: https://www. pca.state.mn.us / water/municipal-stormwater-ms4 (accessed on 18 June 2017).

16. Keeley, M.; Koburger, A.; Dolowitz, D.P.; Medearis, D.; Nickel, D.; Shuster, W. Perspectives on the use of green infrastructure for stormwater management in Cleveland and Milwaukee. Environ. Manag. 2013, 51, 1093. [CrossRef]

17. Derkzen, M.; van Teeffelen, J.A.; Verburg, P.H. Green infrastructure for urban climate adaptation: How do residents' views on climate impacts and green infrastructure shape adaptation preferences? Landsc. Urban Plan. 2017, 157, 106-130. [CrossRef]

18. Gill, S.E.; Handley, J.F.; Ennos, A.R.; Pauleit, S. Adapting cities for climate change: The role of green infrastructure. Built Environ. 2007, 33, 115-133. [CrossRef]

19. Meascham, T.G.; Preston, B.L.; Smith, T.F.; Brooke, C.; Gorddard, R.; Withycombe, G.; Morrison, C. Adapting to climate change through local municipal planning: Barriers and challenges. Mitig. Adapt. Strateg. Glob. Chang. 2011, 16, 889-909. [CrossRef]

20. United States Environmental Protection Agency. Green Infrastructure and Climate Change Collaborating to Improve Community Resiliency; EPA 832-R-16-004; United States Environmental Protection Agency: Washington, DC, USA, 2016.

21. Tuler, S.P.; Webler, T.; Rhoades, J.R. Stormwater management in a time of climate change: Insights from a series of scenario-building dialogues. Weather Clim. Soc. 2016, 8, 163-175. [CrossRef]

22. Federal Emergency Management Agency. Mitigation Ideas: A Resource for Reducing Risk to Natural Hazards. 26 June 2013. Available online: File:/ / /Users / tombeery /Downloads / fema_mitigation_ideas_ final508.pdf (accessed on 19 June 2018).

23. Little, C. (Minnesota Department of Natural Resources, Two Harbors, MN, USA). Personal communication, 8 August 2018.

24. Brown, H.L.; Bos, D.G.; Walsh, C.J.; Fletcher, T.D.; Rakesh, S.R. More than money: How multiple factors influence householder participation in at-source stormwater management. J. Environ. Plan. Manag. 2016, 59, 79-97. [CrossRef]

25. Tompkins, E.L.; Eakin, H. Managing private and public adaptation to climate change. Glob. Environ. Chang. 2012, 22, 3-11. [CrossRef]

26. White, I.; Connelly, A.; Garvin, S.; Lawson, N.; O'Hare, P. Flood resilience technology in Europe: Identifying barriers and co-producing best practice. J. Flood Risk Manag. 2016. [CrossRef]

27. Koerth, J.; Jones, N.; Vafeidis, A.T.; Dimitrakopoulos, P.G.; Melliou, A.; Chatzidimitriou, E.; Koukoulas, S. Household adaptation and intention to adapt to coastal flooding in the Axios-Loudias-Aliakmonas National Park, Greece. Ocean Coast. Manag. 2013, 81, 43-50. [CrossRef]

28. Botzen, W.J.W.; Aerts, J.C.J.H.; van den Bergh, J.C.J.M. Willingness of homeowners to mitigate climate risk through insurance. Ecol. Econ. 2009, 68, 2265-2277. [CrossRef]

29. Botzen, W.J.W.; Aerts, J.C.J.H.; van den Bergh, J.C.J.M. Individual preferences for reducing flood risk to near zero through elevation. Mitig. Adapt. Strateg. Glob. Chang. 2013, 18, 229-244. [CrossRef]

30. Soane, E.; Truss, C.; Alfes, K.; Shantz, A.; Rees, C.; Gatenby, M. Development and application of a new measure of employee engagement: The ISA engagement scale. Hum. Resour. Dev. Int. 2012, 15, 529-547. [CrossRef]

31. Kazmierczak, A.; Bichard, E. Investigating homeowners' interest in property-level flood protection. Int. J. Disaster Resil. Built Environ. 2010, 1, 157-172. [CrossRef] 
32. Soane, E.; Schubert, I.; Challenor, P.; Lunn, R.; Narendran, S.; Pollard, S. Flood perception and mitigation: The role of severity, agency and experience in the purchase of flood protection, and the communication of flood information. Environ. Plan. A 2010, 42, 3023-3038. [CrossRef]

33. Schwartz, J. Cost of Minnesota Flood Estimated at $\$ 100$ Million. New York Times. 22 June 2012. Available online: https:/ / www.nytimes.com/2012/06/23/us/millions-in-damage-from-duluth-flooding.html (accessed on 11 May 2018).

34. Herringshaw, C.J.; Thompson, J.R.; Stewart, T.W. Learning about restoration of urban ecosystems: A case study integrating public participation, stormwater management, and ecological research. Urban Ecosyst. 2010, 13, 535-562. [CrossRef]

35. Lieberherr, E.; Green, O.O. Green infrastructure through citizen stormwater management: Policy instruments, participation and engagement. Sustainability 2018, 10, 2099. [CrossRef]

36. Shandas, V.; Messer, W.B. Fostering green communities through civic engagement: Community-based environmental stewardship in the Portland area. J. Am. Plan. Assoc. 2008, 74, 408-418. [CrossRef]

37. Ekman, K.; Walker, R. Knowledge, Attitudes and Practice (KAP) Survey Summary Report for the Duluth Lakeside Stormwater Reduction Project (LSRP). University of Minnesota. Water Resources Center. 2008. Retrieved from the University of Minnesota Digital Conservancy. Available online: http:/ /hdl.handle.net/ $11299 / 182370$ (accessed on 20 July 2018).

38. Strauss, A.; Corbin, J. Basics of Qualitative Research: Techniques and Procedures for Developing Grounded Theory; Sage Publications, Inc.: Thousand Oaks, CA, USA, 1998.

39. Charmaz, K. Grounded theory: Objectivist and constructivist methods. In Handbook of Qualitative Research, 2nd ed.; Denzin, N.K., Lincoln, Y.S., Eds.; Sage: Thousand Oaks, CA, USA, 2000; pp. 509-535.

40. Watershed Consulting Associates. Vermont Guide to Stormwater Management for Homeowners and Small Businesses; Vermont Department of Environmental Conservation: 2018. Available online: http:/ / dec.vermont. gov/sites/dec/files/wsm/erp/docs/2018-06-14\%20VT_Guide_to_Stormwater_for_Homeowners.pdf (accessed on 20 April 2018).

41. Fortin Consulting; University of Minnesota Sea Grant Program; Natural Resources Research Institute. Field Guide for Maintaining Rural Roadside Ditches: Protecting Lakes and Streams through Proper Ditch Maintenance; University of Minnesota: Minneapolis, MN, USA, 2017.

(C) 2018 by the author. Licensee MDPI, Basel, Switzerland. This article is an open access article distributed under the terms and conditions of the Creative Commons Attribution (CC BY) license (http:/ / creativecommons.org/licenses/by/4.0/). 